DOI: 10.20472/IAC.2020.054.021

J. J. PRINSLOO

NWU Business School, North-West University, South Africa

T. G. PELSER

University KwaZulu-Natal, South Africa

P. S. RADIKONYANA

Municipal Demarcation Board, Pretoria, South Africa

\title{
MARKETING EVOLUTION OF PERFORMANCE ENHANCING DRUGS IN PROFESSIONAL CYCLING
}

\begin{abstract}
:
The use of performance enhancing drugs (PED's) is prevalent amongst professional cyclists. Over the past 100 years, the use there-off went through different evolutionary periods. The products (PED's) evolved since the 1900's. During the early 1900's products like tobacco and alcohol were used. Fifty years later, after WWII, amphetamines (developed during the WWII period) was the product of choice. Since the late 1980's another product evolution took place. Erythropoietin (EPO) a product designed for cancer patients started surfacing amongst cyclists. Ironically this product have one primary negative side effect - sudden death. However, this did not curtail or stop the use. Positive effects were and are massive in terms of athlete performance.

This paper look at the historical time line of the use of PED's. The use there-off as well as the various effects it had and have on cyclists. Marketing (push strategy) did and do not drive this phenomena. Based on its "submerged or underground" nature of products and its use, a "pull strategy" seem to be the chosen marketing channel application. Intermediaries does not fir the accepted marketing profile. Rather medical qualified individuals seem to become links in these distribution channels.

A qualitative literature empirical approach was used. Literature was scrutinised based on a convenient and purposive nature. Because of the sensitive and ethical nature of this paper, a pure qualitative interview approach was disregarded. The aim of this paper was to structure the historical time line as well as the evolution of these products.

The findings, although sensitive, is two-fold in nature. These recommended suggestions are highly speculative and should be treated as alternative suggestions to the current situation.
\end{abstract}

\section{Keywords:}

Performance enhancing drugs (PED's); Tour de France (TdF); Submerged markets; Marketing channel; "Word of Mouth" communication

JEL Classification: M00 


\section{Introduction}

The acceptance of drug use or what has been called a 'culture of tolerance' of drug use in cycling (Waddington: 2000: 163) has been a longstanding feature of professional cycling since the second half of the nineteenth century (Rosen, 2008; Laser, 2015). Given the gruelling nature of cycling and its reliance on cardiovascular perfection, the sport of cycling is a perfect target for drugs that increase athletic performance (Palmer, 2012). Steroid use and the subsequent abuse, for example, are very prevalent in the sport of cycling, particularly in multi-day stage races at high altitude (Brewer, 2002, Marzilli, 2008). Thus, drugs became problematised in the 1960s when their availability increased and national prestige became associated with sporting success (Dimeo, 2008; Waddington, 2005).

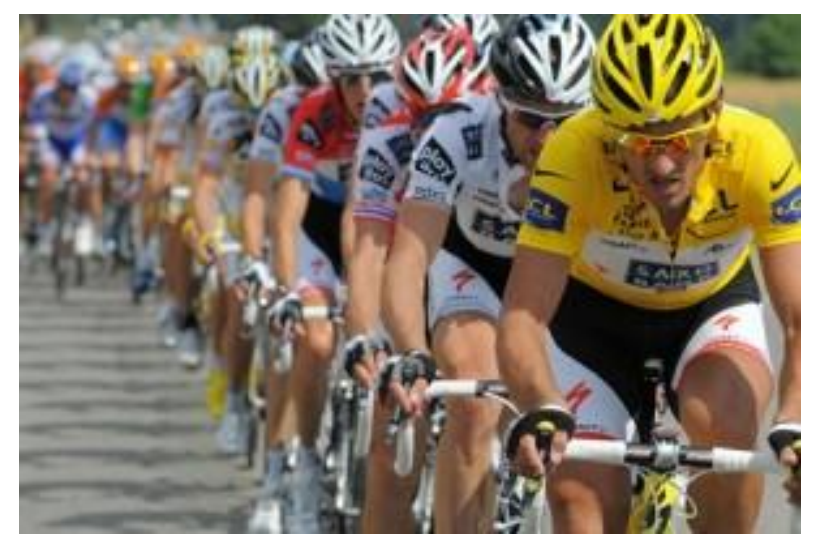

\section{Figure 1: Professional cyclists partaking in a professional cycling tournament}

(http://thesportdigest.com/2012/06/doping-part-of-professional-cyclings-culture): accessed 26 June 2019.

According to a number of writers, historians, and doping experts, the first person to die from doping was Arthur Linton, a British cyclist (Figure 2) who supposedly overdosed on a drug known as "trimethyl" during a derby race, which is a race where cyclists were paced by a motorised bicycle, from Bordeaux to Paris (Rosen, 2008; Marcovitz, 2013). Other athletes include the Danish cyclist, Knut Jensen, who collapsed during a competition at the 1960 Olympics in Rome (Marcovitz, 2013). These are some of the doping incidents which indicate that the use of performance enhancing drugs (PED's) in grand cycling events such as the Tour de France (TDF) has been a pervasive culture or practise since the early 1960s. 


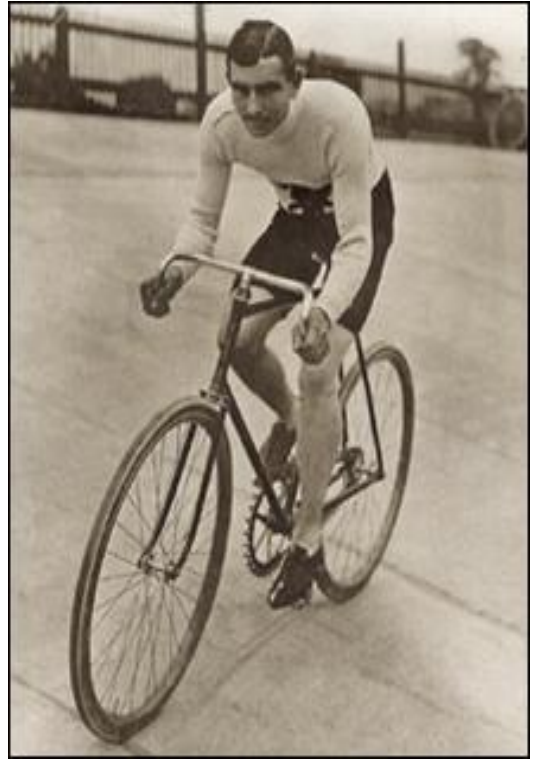

Although not an issue at the time of his death, in the years following, Linton's image was tarnished by speculation that his death was caused by doping. The seeds of the story began in 1897, when Jimmy Michael was banned from racing in Britain due to a doping controversy. It was well known that Michael's and Linton's manager Choppy Warburton would carry a 'little black bottle' of an unknown substance to revive his flagging cyclists. Although no record of the contents of Warburton's bottle was ever discovered it was speculated to be either strychnine or a substance known as 'trimethyl'. Although doping was not illegal under the rules of cycling at the time, and was common in many racing sports

\section{Figure 2: Arthur Linton}

(https://www.podiumcafe.com/bookcorner/2015/5/7/8564379/bordeauxparis-and-the-death-of-arthur-linton) : accessed: 26 June 2019.

Despite attempts to enact stricter regulations and inflict harsher punishments, doping in elite cycling remains prevalent (Fretwell, 2014; Laser, 2015). Rosen (2008) highlights that the pace of doping scandals in competitive cycling quickened from 2000 to present. In February 2015, a report to the President of the UCI, conducted by the Cycling Independent Reform Commission (CIRC), finds that 'a culture of doping continues to exist in the sport of professional cycling - to date, although dopers have moved on to new and more advanced methods to avoid detection' (Cycling Independent Reform Commission, 2015:12). As the lucrative nature of cycling continues to grow, the problem of doping in cycling may never be fully resolved, because cyclists continue to find new and improved ways to illegally enhance their performance in order to achieve fame and success (Hervey, 2015; Laser, 2015).

\section{Problem Statement}

Despite the creation of national anti-doping organizations such as the National Anti-Doping Organisation (NADOs) and the World Anti-Doping Agency (WADA) in 1999, doping scandals continue to tarnish the image or credibility of professional cycling (Verroken, 2005; Marzilli, 2008; Pamel, 2007; Marcovitz, 2013; Fretwell, 2014; De Bruijn et al., 2015; Laser, 2015). The primary objective of these anti - doping organisations, were and are to determine which drugs 
should be outlawed and to set standards for tests - with the hope to ensure a fair playing field. Since 1998, there has been a significant increase in the number of riders who have been suspended for drug-related offences and, relatively recent there have been some signs of what might prove that drug use within professional cycling still remains widespread particularly since the summer of 2007 (Waddington \& Smith, 2009). "While professional cyclists are sanctioned for violating anti-doping rules on an almost regular basis, the investigation and lifetime ban of Lance Armstrong, America's greatest cycling legend, highlighted the serious problems facing the sport" (Fretwell, 2014:206). The problem statement, therefore, is that the misuse of PED's have been a prevalent part of the professional cycling for the last century, and regulators have had a difficult time to stop its use.

\section{Objectives of the study}

- To provide the historical timeline on the use of performance-enhancing drugs in professional cycling from 1800 - to present, and

- to provide substantial anecdotal evidence that the regulators, such as, the World AntiDoping Agency (WADA), for example, have had a difficult time to date to stop the spread of performance-enhancing drug use in professional cycling.

- Brief marketing channel considerations.

\section{Research methodology}

This study followed a qualitative approach. Existing literature was the source of data. This method used was motivated by the ethical sensitivity (use of PED's) of required data.

Purposive sampling, in terms of the scrutinised data, was used. Thus, focus was directed to all relevant data pertaining to the use of PED's in cycling - over time. Data were catagorised and analised based on a selected time period. Mentioned time periods are catagorised as follows: 1800's - 1950's, 1960's, 1970's, 1980's, 1990's and the 2000's until present. In the following section (literature) a snapshot of the use of PED's is presented, as well as the effect it had on cyclists is analised. 


\section{FINDINGS: The use (and marketing) of performance enhancing drugs}

\section{The 1800s until 1950s}

Doping in sport was not as well documented during this time period as it has become in the middle of the nineteenth century, because using drugs as a means to improve one's performance wasn't considered scandalous (Rosen, 2008; Verroken, 2005). At the time, no rules specifically prevented athletes from doping with stimulants or other PED's, because doping wasn't illegal (Yesalis \& Bahrke, 2005). On the contrary, doping was then considered cutting edge (Rosen, 2008). By the 1870s, swimmers, cyclists, distance runners, boxers, and other athletes were using stimulants in order to boost their performance (Rosen, 2008; Golden, 1992). To maintain or increase their energy and prevent fatigue, various trainers and athletes experimented with a wide variety of compounds thought to be stimulants (Rosen, 2008).

By comparison with other classes of drugs, stimulants have probably been misused in sport over the longest period of time (Verroken, 2005). Strychnine, cocaine, caffeine (an active substance which occurs in social drinks such as tea, coffee and cola), alcohol, marijuana, nicotine, opium, heroin, sugar cubes dipped in ether and nitro-glycerine were often the stimulants reported to have been used alone and in combination (Rosen, 2008; Reilly, 2005; Goldman, 1992; Boje, 1939; Hoberman, 1992; Prokop, 1970). These stimulants are considered to have a performance-enhancing effect on endurance athletes, as well as on explosive power activities, because of an increased capacity to exercise strenuously and a reduction in sensitivity to pain (Verroken, 2005). As Verroken (2005) alluded, probably one of the earliest reasons for the use of stimulants was to help athletes through 'the pain barrier'.

According to Verroken (2005), stimulants are more likely to be used on the day of a competition, however, it seems likely that athletes now consider the use of stimulants in training to allow the intensity of the training session to be increased. For most sport disciplines, the use of alcohol would be detrimental to performance, so it is logical that alcohol falls into the category of 'substances prohibited in particular sports' like cycling (Verroken, 2005). Probably the first reported drug-related death in sport was the cyclist Arthur Linton (Figure 2) in 1896, who was reportedly administered strychnine by his coach, who had later been banned from the sport, presumably for his part in doping (Verroken, 2005).

By the mid-1930s, testosterone had been isolated and synthesized, because medical researchers, coaches, trainers and athletes experimented with testosterone as a way of increasing strength and aggressiveness, among other things (Rosen, 2008). During 1935, 
athletes started experimenting with testosterone and other steroids (drugs derived from testosterone) in an effort to improve their performance. Not surprisingly, in the 1940s and 1950s, amphetamines became the drugs of choice for athletes, particularly in sports such as cycling, where the stimulant effects were perceived to be beneficial to enhancing sporting performance in sprint and stamina events (Verroken, 2005). But even so, the use of the older stimulants like caffeine still occurs on a regular basis among certain types of sports such as running, cycling, and swimming (Rosen, 2008).

The idea of performance boosters and performance enhancement was nothing new in the 1950s, as there were athletes who were willing to try new drugs or new doping techniques like testosterone, the use of steroids and stimulants to reduce fatigue in long endurance events at the time (Rosen, 2008). It turns out that at the 1959 World Championships in Holland, Jensen became ill just after finishing the race, and Ole Krøyer, another Danish cyclist, who also competed at the 1959 World Championships later admitted that both he and Jensen had taken stimulants before and during the race which they got from Danish professional cyclist Bent Ole Retvig (Rosen, 2008).

\section{During the 1960s}

According to Johanson (1987), 'drug doping' has become a realistic feature of professional cycling given that 'good' performance can only be denoted by winning. As a result, doping is perceived to be a legitimate path to higher order ambitions in pursuit of increasing the level of success in cycling (Smith, 2017). Verroken (2005), maintains that the phenomenon of drug use in sport such as cycling must be seen in parallel with a 'pharmacological revolution' which began in the 1960s, because the search by pharmaceutical companies for more potent, more selective and less toxic drugs resulted in a vast array of powerful agents capable of altering many biochemical, physiological and psychological functions in the body.

As the 1960s dawned, doping in sports was coming into the public consciousness more and more (Rosen, 2008). The use of anabolic-androgenic steroids (AAS), which cycling refers to as the intermittent use of steroids followed by a drug holiday, is another performance enhancing technique, and this practice of 'cycling' is based on the notion that drug holidays prevent desensitization to large doses of androgen (Basaria, 2010). So, other drugs include agents that build muscle and bone such as anabolic steroids, insulin growth factors, and human growth hormones (Dubin, 2009). 
Still in the 1960s, testosterone and steroid use were spreading out from sports like weight lifting to various disciplines in track and field (Rosen, 2008). The first incident of the 1960s connected to doping, already alluded to involved the tragic death of a young Danish cyclist Knut Jenson at the Rome Olympics in 1960 (Marcovitz, 2013). Some reports claim that the cause of Jensen's death was due to meth-amphetamine and nicoty-nal alcohol, which is a drug or stimulant also known as ronicol or roniacol (Podofdonny, 2005). Another alleged use of blood boosting in sport in the 1960s, was when a French four times winner of the TDF, that is, the long-distance cycling (1961-1964) was named as one of the first cyclists to use the technique (AndrénSanberg, 2016).

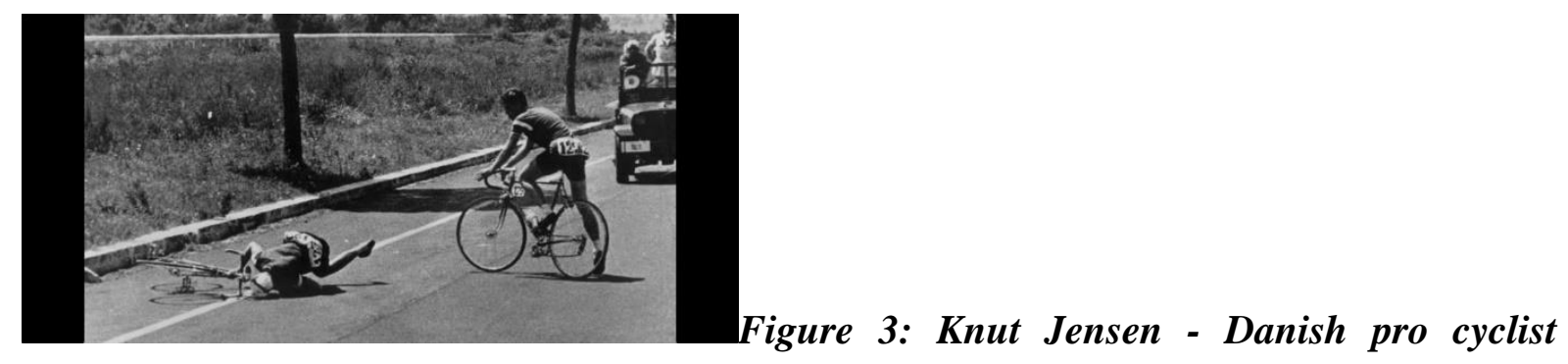

(https://www.sportsintegrityinitiative.com/the-truth-about-knud-revisiting-an-anti-dopingmyth/) accessed: 26 June 2019.

During the 1967 TDF, elite British cyclist Tom Simpson died on the steep ascent of Mont Ventoux in France, allegedly because of the abuse of performance enhancing drugs called amphetamine (Pampel, 2007; Rosen, 2008; Waddington \& Smith, 2009; Marcovitz, 2013;

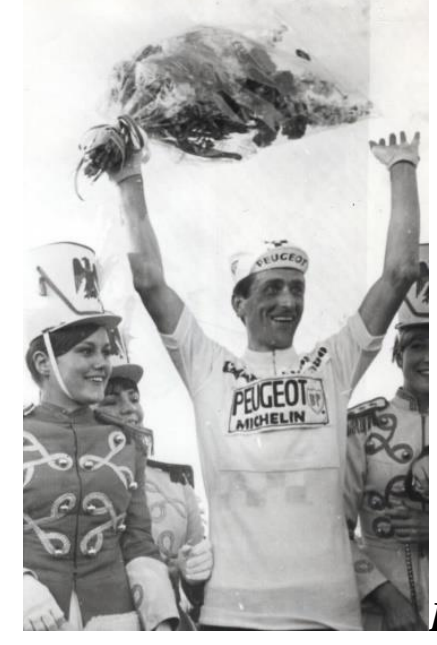

Figure 4: Tom Simpson (https://www.cyclingweekly.com/ news/latest-news/tom-simpson-life-pictures-146298) accessed: 26 June 2019. 
Andrén-Sanberg, 2016). Furthermore, in 1968 a cyclist, Yves Mottin, died from "excessive amphetamine use" two days after winning a race (Andrén-Sanberg, 2016:29). MorenteSánchez and Zabala (2013) highlight that not all cyclists are dopers, because in panic laden environments, high profile cyclists often deny doping through press releases and autobiographies. However, despite this denial, further ambiguity also ensues as the implications of an enforced doping ban mean it becomes difficult to garner the true extent of the problem within professional cycling, because acknowledgement of drug use carries severe career consequences for those concerned (Jones, 2010; Pitsch \& Emrich, 2012). As such, blood doping in cycling is not a personality issue (Wiggins, 2012), but instead the sport's culture and peer pressure imposed on cyclists to adopt any means necessary to win (Stewart \& Smith, 2010).

Furthermore, Walsh and Giulianotti (2001) mention that a doping culture exists in cycling partly due to what they refer to as the 'hyper commodification of sport' whereby both the quantitative value of sport have increased rapidly, in addition to the secondary, non-play aspects that have become commercialized since 1960. Subsequently, given the commodified nature of sport and work, and the spectacle that they have become, incidents of doping can no longer be meaningfully located - solely within a discussion of each cyclist's inappropriate moral standing (Barthes, 1997). As doing so negates equal determinants concerned with the competitive and spectating environment in which they are located.

\section{During the 1970's}

By the beginning of the 1970s, steroids had made inroads into both professional football and professional baseball, while athletes in an ever-expanding circle of sports were using the drugs to excel (Rosen, 2008). In the 1970s, steroids, amphetamine and other drugs were the most commonly used drugs in professional sports, such as cycling and wrestling (Dimeo, 2007; Rosen, 2008).

Consequently, the most international federations had introduced drug-testing in sports by the 1970s. However, the situation certainly did not improve during the 1970s, because Bernard Thévenet, the 1975 and 1977 TDF winner, later admitted he used cortisone (Andreff, 2016; Rosen, 2008). As Andreff (2016) states, Michel Pollentier was the first yellow jersey wearer disqualified for doping, but was excluded from the $1978 \mathrm{TDF}$, when he tried to cheat in a doping test. Joop Zoetemelk, the 1980 Tour de France winner, is the only rider to have tested 
positive no less than three times during the Tour de France: in 1977, in 1979 and in 1983 (Andreff, 2016).

Édouard Louis Joseph, baron Merckx better known as Eddy Merckx, is a Belgian former professional road and track bicycle racer, who is widely seen as the most successful rider in the history of competitive cycling. His victories include an unequalled eleven Grand Tours (TDF - 5, Giro (Italy) - 5 and Vaulto (Spain) - 1), all of the five Monuments, three World Championships, the hour record, every major one-day race other than Paris-Tours, and extensive victories on the track. However, on 8 May 1977, Merckx, along with several other riders, tested positive for pemoline, a stimulant in Stimul, at La Flèche Wallonne and the group of riders were charged by the Belgian cycling federation. All these riders were each given a 24,000 pesetas fine and a one-month suspension. Years later, Merckx admitted he did take a banned substance, citing that he was wrong to have trusted a doctor.

\section{During the 1980's and 90's (decadent period)}

The two most common performance enhancing techniques in cycling, during the 80's and beyond) were blood-doping and erythropoietin (EPO) (Smith, 2017). The former, concerns the removal, storage and re-injection of an athlete's own blood to increase the amount of oxygen that they are able to intake via an increase in red blood cells (Schjerling, 2005). The latter, $\mathrm{EPO}$, is a type of growth hormone that stimulates the athlete's bone marrow to produce more red blood cells, also increasing the level of oxygen in their blood (Waddington \& Smith, 2000; Hailey, 2011).

The 1980s ushered in the sudden and immense commercialization of the sport of cycling (Laser, 2015; Waddington \& Smith, 2009). As the sport of cycling entered the 1990s, companies began pouring advertising dollars into the hands of teams as the world began to take note of cycling as a legitimate spectator sport (Wilcockson, 2006). With these newfound resources, teams were not able to utilise new technologies, thus were more willing to assume certain risks on the path towards success (Laser, 2015). Also, with the presence of rogue doctors and other medical professionals, cycling continued on its slide away from sport, into a sort of "performance-enhancing pharmacology" (Laser, 2015:79; Sonksen, 2001; Rosen, 2008). Doping is therefore not a solitary act and that many stakeholders including professional cyclists, the media, officials and team doctors all play a significant role in the definitional process (Lauber, Jamieson \& Krohn, 2010). 
Besides the first anecdotal reports in the 1960s, the technique of blood doping became fairly popular during the 1980s and 90's, and it was widely used by distance runners, cyclists, and skiers, particularly during the 1980 and 1984 Olympics (Rosen, 2008). It was during the 1980s that cyclists, such as those in the U.S. cycling team during the 1984 summer games found a common method of blood doping, called EPO - to be most effective when taken regularly over long training periods (Rosen, 2008; Hailey, 2011). One of the cyclists, twenty-seven-year-old Johannes Draaijer, who finished $20^{\text {th }}$ in the 1989 TDF died of a heart attack in his sleep (Rosen, 2008), and this incident also demonstrates how pervasive the drug abuse in professional cycling had become in the 1980s (Verroken, 2005).

Mass industrialised doping penetrated cycling and the TDF during the 1990s (Andreff, 2016). In the early 1990s, after EPO doping gained popularity but before tests for its presence were available, several Dutch cyclists died in their sleep due to inexplicable cardiac arrest (Savulescu, Foddy \& Clayton, 2004), and as Cazzola (2000) states, this has been attributed to high levels of EPO doping. Bjarne Riis, the 1996 Tour de France winner (who admitted doping in 2007), and acquired the nickname of "Mr 60 percent" which referred to his hematocrit level, is another doping incident in the 1990s (Andrén-Sanberg, 2016:29). The Festina scandal at the TDF in 1998 was the biggest doping scandal to date in the world of professional cycling - when law enforcement official's uncovered testosterone, human growth hormone, and EPO in the car belonging to a team employee. This provided proof of organised and widespread doping in professional cycling (Christiansen, 2005; Rosen, 2008; Laser, 2015; Andrén-Sanberg, 2016). The 1998 TDF, therefore, has been the most consistently drug-soaked sport of the twentieth century (Hoberman, 1998).

From 1999 to 2005, Lance Armstrong was crowned champion of the TDF (seven times), more than any other cyclist in history, however, on 10 October 2012, his history of performance enhancing drug use was brought to light by the United States Anti-Doping Agency (USADA) (De Bruijn, Groenleer \& Van Ruijven, 2015; Laser, 2015; USADA, 2012). 


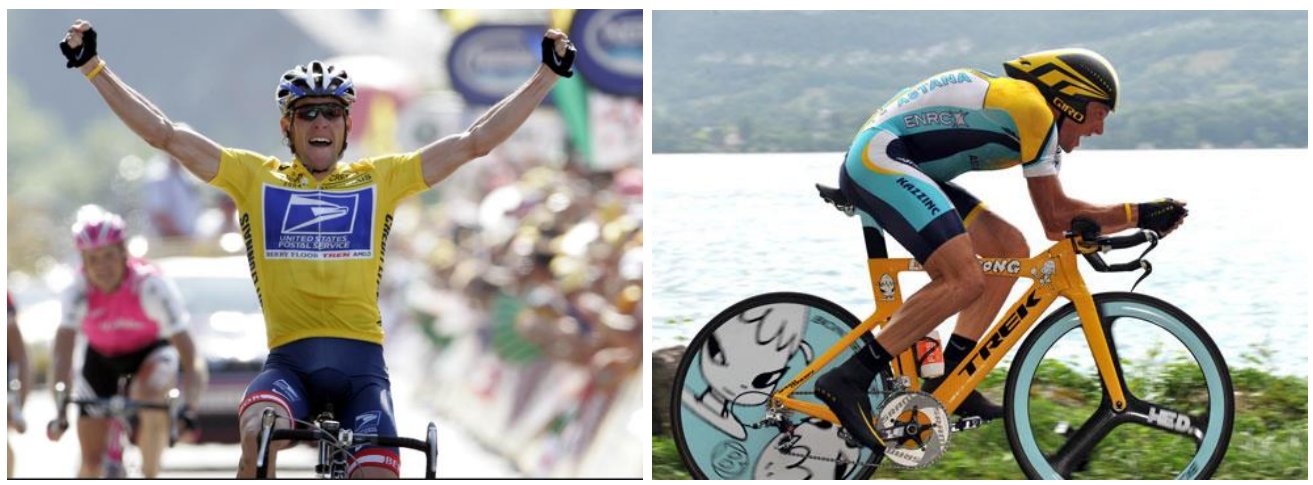

Figure 5: Lance Armstrong, the seven times champion of the TDF

(https://www.theguardian.com/sport/2015/mar/09/lance-armstrong-cycling-doping-scandal) accessed: 26 June 2019.

The revelations about drug use in the 1998 TDF publicly revealed the extent of drug use in cycling, but long before that Tour there was already an abundance of data to indicate that drug use in cycling was widespread (Waddington \& Smith, 2009). In 1990, already five cyclists died under mysterious circumstances, possibly connected to the use of EPO (Rosen, 2008). The rise of custom-tailored performance-enhancing drugs known as EPO or blood transfusions were very common in international professional cycling during the $1990 \mathrm{~s}$ and early $2000 \mathrm{~s}$ (Hoberman, 2001; Rosen, 2008; Andrén-Sanberg, 2016), because teams were willing to risk sanctions or even punishments as severe as major fines or suspensions in the pursuit of victory. Perhaps unsurprisingly the prevalence of doping in cycling remains, and especially in Grand Tours, because from 1996 to 2010 thirty-six out of forty five top three finishers in the TDF were caught doping (USADA, 2013).

\section{During the 2000's to date}

In 2001, Spanish cyclist Txema del Olmo was the only athlete who tested positive for EPO and who was subsequently banned from the Tour (Andrén-Sanberg, 2016). The 2003 year's TDF ended with no big surprises as only one athlete was found to be using the performanceenhancing drug known as EPO (Andrén-Sanberg, 2016). Indeed, the Tour might have become cleaner since the infamous 1998 race when the whole Italian Festina team were disqualified possession of doping products, including EPO. However, in 2006, the American cyclist Floyd Landis who won the TDF was stripped of the title when allegedly tests positive for testosterone (Marcovitz, 2013; Rosen, 2008). According to Rosen (2008), the cyclist Michael Rasmussen, who was leading the TDF was withdrawn and subsequently fired in June 2007 by his team after 
problems related to missed anti-doping tests conducted by UCI (the governing body of cycling) were uncovered (Rosen, 2008).

The most recent high profile instance of doping materialised in June 2012 when the USADA charged Lance Armstrong, the seven times TDF winner - for doping between 1998 and 2011 (USADA, 2012). Again, in 2012 alone, the USADA sanctioned seventeen American cyclists for the use of performance enhancing substances (US Anti-Doping, 2014). Andreff (2016) concludes that the 1998-2010 period can easily be qualified as the darkest period ever for the Tour de France with the ex post disqualifications of Armstrong, Landis and Contador, and the Tour losing nine out of its twelve final yellow jersey winners between 1999 and 2010 .

The international anti-doping agencies have had a difficult time to stop the spread of performance-enhancing drugs in professional cycling

In response to the immense rise in doping publicity over the past several decades, the decade of 1960-1970 was marked by many historical events opposed to doping, such as the creation of a council, composed of 22 nations, and proposing a resolution against the use of doping agents in sports (Marzilli, 2008; Andrén-Sanberg, 2016). According to Laser (2015) and Chadwick (2013), the preeminent regulatory agency for the sport of cycling - International Cycling Union (UCI), has been particularly harsh when punishing cyclists found to have used performance-enhancing drugs (Connor, 2014). The cases such as of Armstrong's when he was sanctioned from professional cycling for life are examples of harsher punishments imposed by the UCI against the abuse of drugs in professional cycling (Fretwell, 2014; Laser, 2015).

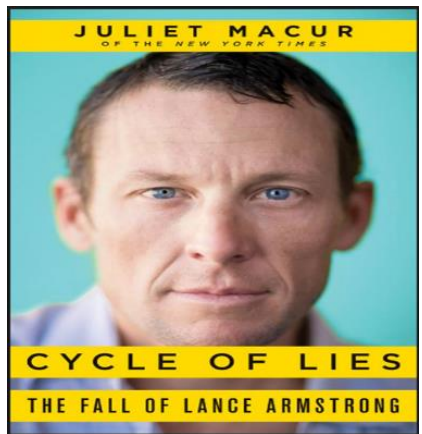

Figure 6: Fall of Lance Armstrong due to sanctions by UCI (https://www.theguardian.com/books/2014/mar/10/cycle-of-lies-review-juliet-macur-lancearmstrong) Accessed: 26 June 2019. 
According to Dimeo (2014), anti-doping campaigns in sport in the 1990s were lacking systematic effort to tackle doping which was tacitly tolerated by spectators. As a result, the international fight against doping was a fragmented affair. The International Olympic Committee, for example, was providing some leadership, but focused mainly on the quadrennial Games and lacked any significant influence on professional cycling (Dimeo, 2014). The testing system varied across sport and place, such that some competitors were rarely tested and most sports only focused on in-competition testing, allowing dopers free rein to consume banned drugs during their training periods (Dimeo, 2014). On the one hand, in response to 'blood doping' during the 1990s, the UCI, FIFA and the IOC introduced the direct urine test and the sampling of blood to detect blood manipulation, as evidenced by direct and indirect parameters (Rosen, 2008). On the other hand, Hermann and Henneberg (2014), however, have determined that to detect $100 \%$ of doping instances over a one-year period, 16-50 tests would need to be carried out on each athlete.

In the midst of anti-doping tests since in the 1970s, doping cases still emerged to the present. Floyd Landis, for example, who won the $2006 \mathrm{TdF}$, by securing his ultimate victory during Stage 17 of the race (Biography Channel, 2014), later tested positive for synthetic testosterone, and was stripped of his title, and banned from cycling for two years (Biography Channel, 2014). The suspension of several professional road cyclists from the 2006 TDF could represent the tip of the iceberg, with more than 200 athletes in different sports disciplines implicated in an international doping probe including blood transfusions and exogenous hormone administration (Lippi \& Banfi, 2006). Di Luca, an Italian cyclist, was also accused of doping for many years and was suspended for three months during the off-season in 2007-2008 for his involvement in an Italian doping case (Cycling News, 2011). Alberto Contador, a three-time TdF Champion, tested positive for clenbuterol, a muscle building and weight-loss drug, during the 2010 Tour (Austen, 2010). As a result, Contador was ultimately suspended for two years and stripped of his 2010 Tour victory, in addition to his twelve other titles (Austen, 2010).

Frank Schleck, who finished third in the 2011 Tour de France, was forced to drop out of the 2012 race, five stages from the end for testing positive for the diuretic Xipamide (USA Today, 2013). Lance Armstrong, one of the sport's most infamous riders, won seven consecutive TdF titles after battling advanced testicular cancer (Biography Channel, 2014), was faced with numerous doping allegations throughout his career. In 2012, USADA brought formal charges against him (Biography Channel, 2014). Since, Armstrong's charge and acquittal, many more 
doping confessions and scandals have shown that this deemed illegitimate practice maintains prevalence among professional cyclists, despite zealous anti-doping campaigns that are costly, but yet do not eradicate the private motives for usage (Jones, 2010). Therefore, the failings of anti-doping to 'level the playing field' are evident in the number of tests Armstrong and other riders 'passed', and in the confidence sports doctors had in planning dosages in such a way as to circumvent the testing system (Hoberman, 2003). These fallacies often translate to an inefficiency of testing system for the use of performance enhancing drugs in endurance sports such as professional cycling (Smith, 2017).

\section{Physical effects of performance enhancing drugs}

Figure 1 is a simple indication of individual performance (power to weight) increase over time. This can simply be based on advanced training techniques since the late 80 's. The alternative can also be considered, based on literature, which suggest and confirm the use of performance enhancing drugs. The use of EPO became prevalent (literature based) during the late 1980's, throughout the 1990's and into the 2000's. Although a 50\% cut-off in terms of haematocrit health safety has been set by authorities, Pantani registered over $60 \%$ while racing the Giro, during the height of his career.

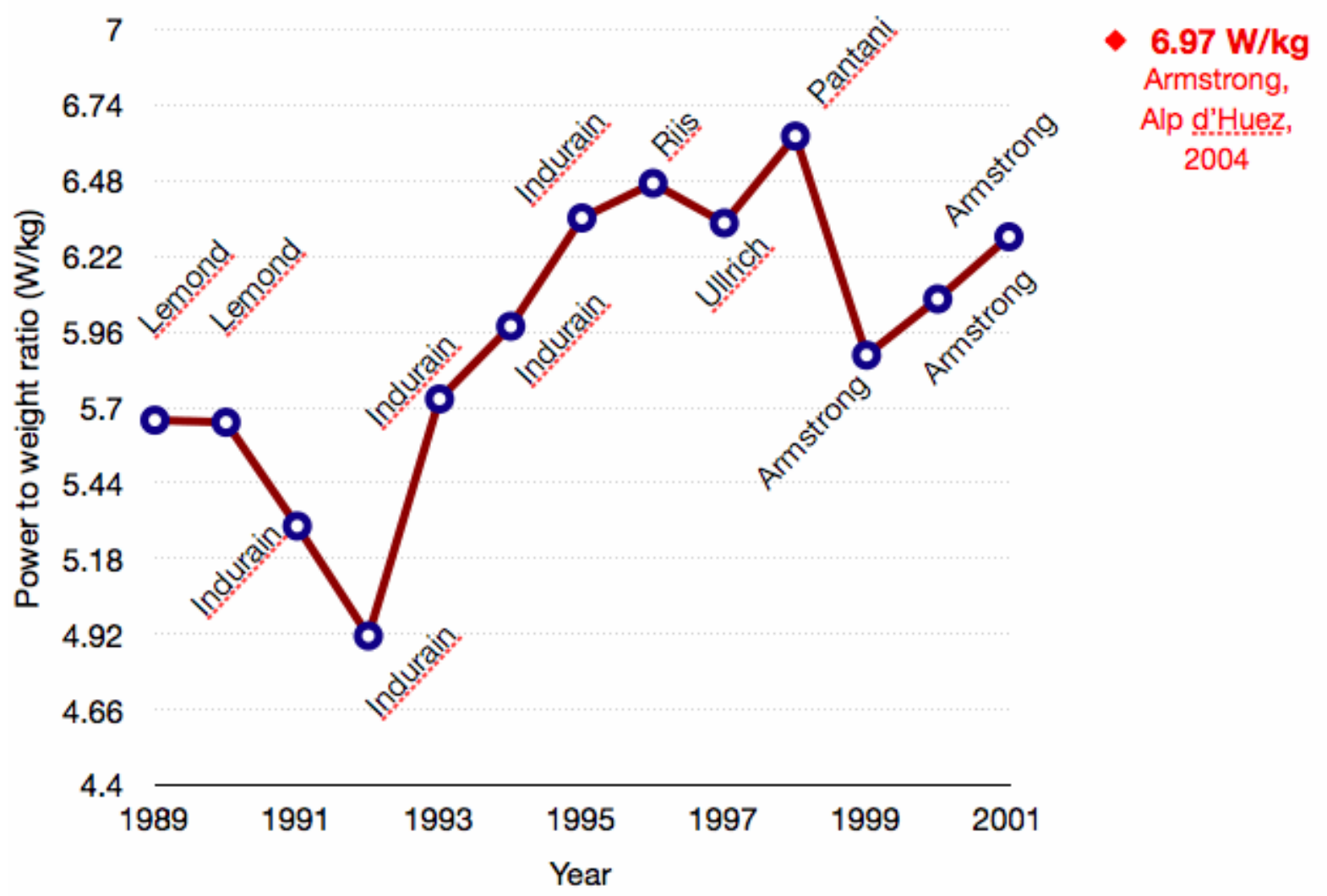


Figure 7: Power output (https://sportsscientists.com/2009/07/tour-de-france-2009-powerestimates/) Accessed: 26 June 2019.

Figure 2 is indicative of power output, before and after the use of PED's. In this case it specifically refer to EPO. A massive increase in capability must be a considered motivator for any professional cyclist.

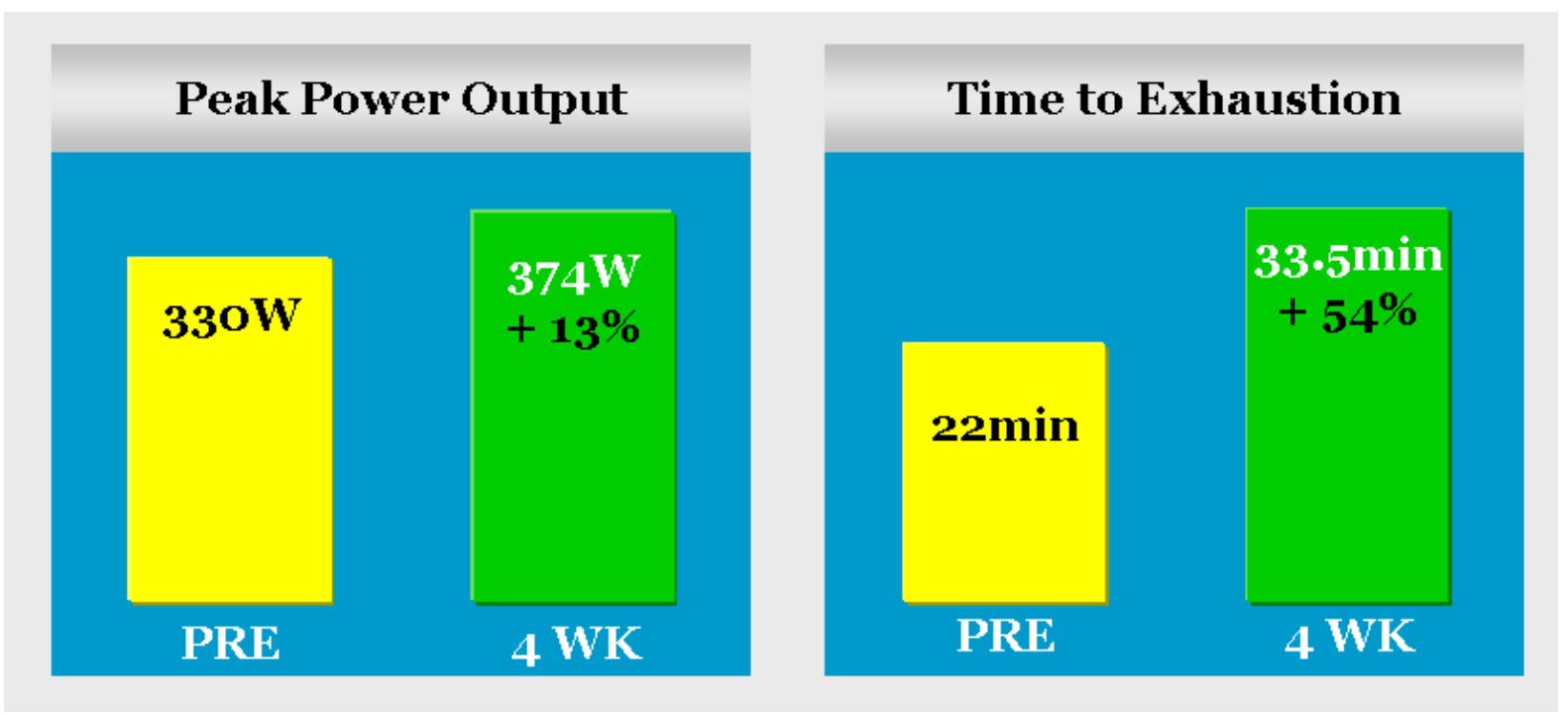

Figure 8: Increase of power (W) and time to exhaustion (https://sportsscientists.com /2007/11/the-effect-of-epo-on-performance/?doing_wp_cron=1561538467.91056394 577026 367 18750). Accessed: 24 June 2019.

Some extracts from the Cycling weekly reflect high level pro cyclists consistent use of PED's, regardless of the efforts made by WADA:

Alejandro Valverde could be handed Vuelta a España stage victory after Juan José Cobo found guilty of doping (https://www.cyclingweekly.com/news/racing/vuelta-aespana/alejandro-valverde-handed-vuelta-espana-stage-victory-juan-jose-cobo-found-guiltydoping-427722\#suTX8TIJQ37wkjyS.99). 
Two riders have been caught taking EPO at a New York sportive: One rider tried to avoid detection by pretending to be his own twin brother, who was also taking part in the event (https://www.cyclingweekly.com/news/latest-news/two-riders-caught-taking-epo-new-yorksportive-427655\#WzCl4W3SK2eX1Lgk.99).

Anti-doping laboratory refining test for micro doses of EPO: The new test should allow EPO to be detected up to 48-hours after administration (https://www.cyclingweekly.com/news/ latest-news/anti-doping-laboratory-refining-testmicrodoses-epo-427145\#tgWKpbZv BQ7X2Bp2.99).

\section{UCI carries out 1,300 'rigorous' motor doping tests at Giro d'Italia 2019:}

The governing body used magnetic scanning and X-ray technology during the three weeks (https://www.cyclingweekly.com/news/racing/giro-ditalia/uci-carries-1300-rigorous-motordoping-tests-giro-ditalia-2019-426279\#qY0c514ziGCrF8Sb.99).

Literature is riddled with direct references made to the use of PED's in cycling. The Tour de France must be one of the first sporting events where doping was used. Since the 1900's riders were drinking wine and using strychnine to "dull the pain". During WWII amphetamines was introduced - originally developed to assist soldiers in battle (stay alert and focused). Professional cyclists started "pulling" this product through the distribution channel. Tom Simpson, who died near the summit of Mont Vontoux during the 60's is credited with the following quote: I know from the way they ride the next day that they are taking dope. I don't want to have to take it - I have too much respect for my body - but if I don't win a big event soon, I shall have to start taking it.

Jacques Anquetil (5 time Tour winner) reportedly perfected the use of "the Anquetil cocktail" - comprising of a painkiller, morphine and palfium, injected directly into painfull muscles (even whilst cycling). Amphetamines were used to offset the somnolent effect of morhine, and then a sleeping tablet (Gardenal) was used, allowing to sleep when the stimulatory effects of amphetamines were still active. Anquetil's recorded comment: "You would have to be an imbecile or a crook to imagine that a professional cyclist who races 235 days a year can hold the pace without stimulants". He is further credited with the following statement: "For 50 years bike racers have been taking stimulants. Obviously we can do without them in a 
race, but then we will pedal 15 miles an hour (instead of 25), since we are constantly asked to go faster and to make even greater efforts, we are obliged to take stimulants".

A more recent quote from Jesus Manzano who acknowledges that statements are sometimes inspired by ulterior motives or even sour grapes, who was banned during 2004 for using doping products, summarise it as follows: “They said that I was a rotten apple, but I now believe that the whole tree is rotten. When you train a lot your haematocrit goes down, so how is it possible for someone to go to the Dauphine or the Giro with a (haematocrit) level of 52\%. How do they get it up to that level? With EPO." Manzano lay this at the feet of the ICU (Union Cycliste Internationale). He further said that....”The only ones who are getting rich are some of the doctors, and not the cyclists....”.

\section{Theoretical recommendations}

Based on the historical time line of the used of performance enhancing drugs, simply two options seem to exist:

- The use of performance drugs should be allowed with minor control measures.

○ Various motivations for this option do exist - from health issues to equal competition. However, there is no proof (in the literature) that this phenomena could be stopped or even slightly controlled. The minor control measure could consider a proper sport scientist or medical practitioner as guardian of the cyclists.

- This seem to be a case of ethics and acceptable ethics. If this approach could be considered, various aspects should be taken into consideration.

- Controlling bodies should apply the "no use of drugs" objectively and honestly. Controlling measures should simply imply a life ban when a cyclist is caught using performance enhancers. No exception whatsoever.

○ This approach reflect a perfect sporting world. Highly improbable, but similarly a noble idea.

\section{Conclusion}

Performance enhancing drugs has been in professional cycling for at least the past 100 years. This seem to be a submerged market with no official business networks. There is not a formal business- or marketing plan in place. Rather a "pull strategy" do seem to exist. This could be linked to a submerged or informal business market. The evolutionary marketing effect is based 
on the acquired knowledge by cyclists. The cyclists seem to pull identified medicinal products (PED's) through a "submerged" distribution channel.

The distribution channel is developed on the back of the athlete's knowledge and information sharing. The distribution line seem to consist of producers (unknowingly), Medical practitioners (doctors, sport scientists, generally informed individuals etc.), and finally the client...in this case the professional cyclists. Marketing communication is primarily based on "word of mouth" amongst relevant parties. In all cases, it seems that a prime price is asked and expected for these products.

Whether these products form part of a formal marketing channel or not, they have been used for a long time and might be used for a long time to come. Finally two quotes from Lance Armstrong:

July 1999: "I have been on my deathbed, and I'm not stupid. I can emphatically say I am not on drugs."

Jan 2013: "All the fault and all the blame here falls on me. I viewed this situation as one big lie that I repeated a lot of times. I made my decisions. They are my mistakes, and I am sitting here today to acknowledge that and to say I'm sorry for that."

\section{References}

Andreff, W., 2016. Chapter X: The Tour de France: a success story in spite of competitive imbalance and doping. The Economics of Professional Road Cycling. 978(3), 319-343.

Andrén-Sanberg, Å. 2016. The History of Doping and Antidoping-A systematic collection of published scientific literature 2000-2015. Sweden: Karolinska Institutet at Karolinska University Hospital.

Austen, I., 2010. Tour de France Winner Found Guilty of Doping, N.Y, TIMES (Feb. 6, 2012). 
Barthes, R., 1997. The Eiffel Tower, and Other Mythologies. Berkeley, CA: University of California Press.

Basaria, S., 2010. Androgen abuse in athletes: detection and consequences. The Journal of Clinical Endocrinology \& Metabolism, 95, 1533-1543.

Biography Channel, 2014. Lance Armstrong, Biography. Available from: http://www.biography.com/print/profile/lance-armstrong9188901/accessed-13/08/2014.

Boje, 1939. The Effect of Alcohol and Some Drugs on the Capacity for Work. Acta Physiologica Scandinavica. 15(2), 109-113.

Brewer, B. D., 2002. Commercialization in Professional Cycling 1950-2001: Institutional Transformations and the Rationalization of "Doping," 19 Soc. of Sport Journal. 276-284.

Cazzola M., 2000. A global strategy for prevention and detection of blood doping with erythropoietin and related drugs. Haematologica, 85:561-563.

Chadwick, S., 2013. Market-driven Morality. The Economist, 22 April. [Online] Available from:http://www.economist.com/blogs/gametheory/2013/04/corruption-sport-0?fsrc=nlw |newe|4-222013|5582513|37184323|EU./accessed-03/03/2018.

Christiansen, A. V., 2005. The Legacy of Festina: Patterns of Drug Use in European Cycling Since 1998. Sport in History. 25(30), 497-514.

Connor, T., 2014. An Analysis of the Long-Term Effects of Performance-Enhancing Drugs, VELONEWS.COM, http://velonews.competitor.com/2014/02/training-center/an-analysis-ofthe-long-term-effects-of-performance-enhancing-drugs_317590/3.

Cycling Independent Reform Commission, 2015: CYCLING INDEPENDENT REFORM COMMISSION REPORT - UCI. [Online] Available from: www.uci.ch/mm/Document/ News/CleanSport/16/87/99/CIRCReport2015_Neutral.pdf/accessed-09/03/2018.

Cycling News, 2011. Di Luca Set to Ride for Free with One Year Katusha Deal, (Jan. $\quad 10$, 2011, 9:44 AM).

De Bruijn, H., Groenleer, M. \& Van Ruijven, T., 2015. The dynamics of doping: Lance Armstrong, the United States Anti-Doping Agency and the regulatory governance of professional cycling. Regulation \& Governance. Netherlands: Wiley Publishing Asia Pty Ltd. 
Dimeo, P. The truth about Knud: revisiting a anti-doping myth. https://www.sportsintegrityinitiative.com/the-truth-about-knud-revisiting-an-anti-dopingmyth/ - accessed: 26 June 2019.

Dimeo, P., 2007. A History of Drug Use in Sport - 1976-1976 - Beyond Good and Evil. London: Routledge.

Dimeo, P., 2014. Why Lance Armstrong? Historical Context and Key Turning Points in the 'Cleaning Up' of Professional Cycling. The International Journal of the History of Sport. 31(8), 951-968.

Doping Part of Professional Cycling's Culture. 2012. http:// the sportdigest. com/2012/06/doping-part-of-professional-cyclings-culture/ - accessed: 26 June 2019.

Dubin, A. H., 2009. Performance-Enhancing Drugs. In Press, J. M., McGill, S. M., Prather, H., Tarnopolsky, M. A., Dubin, A. H. and Doherty, T. J. (Eds), Opening the Black Box: The Mysteries of Therapeutic Exercise Unlocked...Rochester: American Association of Neuromuscular \& Electrodiagnostic Medicine (AANEM), 29-34. [Online] Available from: https://pdfs.semanticscholar.org/eddf /dfbdfad86642fb8c6f3c73e5de977e940018.pdf/ accessed-09/03/2018.

Fotheringham, W. 2015. Timeline: Lance Armstrong's journey from deity to disgrace. https://www.theguardian.com/sport/2015/mar/09/lance-armstrong-cycling-doping-scandal accessed: 26 June 2019.

Fretwell, K., 2014. Shutting down the Pharmacy on Wheels: Will Lance Armstrong's Admission Impact the Practice of Doping in Professional Cycling? Pace, Intellectual Property. Sports \& Entertainment Law Forum. 4(1), 175-207.

Goldman B., 1992. Death in the Locker Room/drugs and sports. Illinois: Elite Sports Medicine Publications.

Hailey, N., 2011. A False Start in the Race against Doping in Sport: Concerns with Cycling's Biological Passport. Duke Law Journal. 61, 393-432. Available from: https://scholarship.law.duke.edu/dlj/vol61/iss2/3/accessed-15/08/2014.

Hamilton, T. \& Coyle, D., 2012. The Secret Race: Inside the Hidden World of the Tour de France: Doping, Cover-ups, and Winning at All Costs. London: Transworld.

Hermann, A. \& Henneberg, M., 2014. Anti-Doping Systems in Sports are Doomed to Fail: A Probability and Cost Analysis. Sports Medicine \& Doping Studies. 4(5), 1-12. 
Hervey, L., 2015. Cycling salaries: how much do professional cyclists earn?, Sky Sports. [Online] Available from: www.skysports.com/cycling/news/ 21683/991 4043/just-howmuch-do-chris-froome-and-the-rest-of-the-peloton-earn/access ed-09/03/2018.

Hoberman, J., 1992. Mortal Engines: The Science of Performance and the Dehumanization of Sport. New York: Free Press.

Hoberman, J., 1998. A Pharmacy on Wheels - The Tour De France Doping Scandal, MESORX. [Online] Available from: http://thinksteroids.com/articles/festina- tour-de-francedopingscandal/.

Hoberman, J., 2001. How Drug Testing Fails: The Politics of Doping Control. In Wilson, W. \& Derse, E. (Eds.). Doping in Elite Sport: The Politics of Drugs in the Olympic Movement. United States: Human Kinetics Publishers, Inc.

Hoberman, J., 2003. “'A Pharmacy on Wheels': Doping and Community Cohesion among Professional Cyclists Following the Tour de France Scandal of 1998.” In

https://www.cyclingweekly.com/news/ latest-news/anti-doping-laboratory-refining-testmicrodoses-epo-427145\#tgWKpbZv BQ7X2Bp2.99 - accessed 21-06-2019.

https://www.cyclingweekly.com/news/latest-news/two-riders-caught-taking-epo-new-yorksportive-427655\#WzCl4W3SK2eX1Lgk.99 - accessed 21-06-2019.

https://www.cyclingweekly.com/news/racing/giro-ditalia/uci-carries-1300-rigorous-motordoping-tests-giro-ditalia-2019-426279\#qY0c514ziGCrF8Sb.99 - accessed 21-06-2019.

https://www.cyclingweekly.com/news/racing/vuelta-a-espana/alejandro-valverde-handedvuelta-espana-stage-victory-juan-jose-cobo-found-guilty-doping-

427722\#suTX8TIJQ37wkjyS.99 accessed 21-06-2019.

Johanson, M., 1987. Doping as a threat against sport and society: The case of Sweden. International Review for the Sociology of Sport. 22, 83-97.

Jones, C., 2010. Doping in cycling: Realism, antirealism, and ethical deliberation. Journal of the Philosophy of Sport. 37, 88-101.

Laser, T., 2015. Doping in Cycling: Incentivizing the Reporting of UCI Anti-Doping Rules Violations through Organizational Oversight and Accountability. The John Marshall Law Review. 49(2), 624-654. 
Lauber, M., Jamieson, K. \& Krohn, M., 2010. Newspaper reporting and the production of deviance: Drug use among professional athletes. Deviant Behaviour, 14:317- 339.

Lewis, T. 2014. Cycle of Lies review - Juliet Macur's unflattering portrait of Lance Armstrong. https://www.theguardian.com/books/2014/mar/10/cycle-of-lies-review-juliet-macur-lancearmstrong - accessed: 26 June 2019.

Lippi, G. \& Banfi, G., 2006. Blood transfusions in athletes. Old dogmas, new tricks. Clinical Chemistry Laboratory Medicine, 44, 1395-1402.

Marcovitz, H., 2013. How Serious a Problem Is Drug Use in Sports? United States: ReferencePoint Press, Inc.

Marzilli, A., 2008. Drugs and Sports. New York: Infobase Publishing.

McKay, 2015. Bordeaux-Paris and the death of Arthur Linton. https://www.podiumcafe.com/book-corner/2015/5/7/8564379/bordeaux-paris-and-the-deathof-arthur-linton - accessed: 26 June 2019.

Møller, V. \& Nauright, J. (Eds.). The Essence of Sport. Odense: University of Southern Denmark Press, 107-127.

Møller, V., 2010. The Ethics of Doping and Anti-Doping: Redeeming the Soul of Sport? London: Routledge.

Morente-Sánchez J and Zabala M (2013) Doping in sport: A review of elite athlete's attitudes, beliefs and knowledge. Sports Medicine. 43, 395-411.

Palmer, B., 2012. Riding High: Why Is There So Much More Doping in Cycling Than in Other Sports?

Pampel, F. C., 2007. Drugs and Sports (Library in a book). New York: Infobase Publishing.

Pitsch, W. \& Emrich, E., 2012. The frequency of doping in elite sport: Results of a replication study. International Review for the Sociology of Sport. 47, 559-580.

Prokop, L., 1970. The Struggle against Doping and its History. Journal of Sports Medicine and Physical Fitness. 10(1), 45-48. 
Reilly, T., 2005. Alcohol, anti-anxiety drugs and sport. In Mottram, D. R. (Ed.) Drugs in Sport. $4^{\text {th }}$ Edition. London: Routledge Taylor \& Francis, 258-287.

Rosen, D. M., 2008. A History of Performance Enhancement in Sports from the Nineteenth Century to Today. London: Praeger Publishers.

Ross. 2007. The Science of Sport. The effect of EPO on performance: who wouldn't want to use it? https://sportsscientists.com/2007/11/the-effect-of-epo-on-performance/? doing wp_cron= 1561538467.9105639457702636718750 - accessed: 26 June 2019.

Ross. 2009. The Science of Sport. Tour de France Power estimates: what does it take to climb with the elites? https://sportsscientists.com/2009/07/tour-de-france-2009-power-estimates/ accessed: 23 June 2019.

Savulescu, J., Foddy, B. \& Clayton, M., 2004. Why we should allow performance enhancing drugs in sport? British Journal of Sports Medicine. 38(6), 666-670. Available from: https://bjsm.bmj.com/content/38/6/666/accessed-13/08/2014.

Smith, C., 2017. Tour du dopage: Confessions of doping professional cyclists in a modern work environment. International Review for the Sociology of Sport. 52(10), 97-111.

Sonksen, P. H., 2001. Insulin, growth hormone and sport. Journal of Endocrinology, 170, 1325.

Stewart, B. \& Smith, A., 2010. The role of ideology in shaping drug use regulation in Australian sport. International Review for the Sociology of Sport. 45, 187-198.

United States Anti-Doping Agency (USADA), 2012. Report on proceedings under the World anti-doping code and the USADA protocol. Available from: http://d3epuodzu3wuis.cloudfront.net/ReasonedDecision.pdf/accessed-13/08/2014.

US. Anti-Doping, 2014. [Online] Available from: http://www.usada.org/sanctions/ accessed25/02/2014.

USA Today, 2013. Frank Schleck Given 1-Year Doping Ban, (Jan. 30, 2013, 5:34 PM).

USADA, 2013. 
Verroken, M., 2005. Drug use and abuse in sport. In Mottram, D. R. (Ed), Drugs in Sport. $4^{\text {th }}$ edition. London: Routledge Taylor \& Francis Group, 29-62.

Waddington I and Smith A (2009) An Introduction to Drugs in Sport: Addicted to Winning? New York: Routledge.

Waddington, I. \& Smith, A., 2000. Sport, Health and Drugs: A Critical Sociological Perspective. London: Routledge.

Waddington, I., 2000. Sport, Health and Drugs: A Critical Sociological Perspective. London: Spon.

Waddington, I., 2005. Changing patterns of drug use in British sport from the 1960s. Sport in History. 25, 472-496.

Walsh, A.J. \& Giulianotti, R., 2001. This sporting Mam-mon: a normative critique of the commodification of sport. Journal of the Philosophy of Sport. 28(1), 53-77.

Walters, J.E. 2017. Tom Simpson 1937-1967: A life in pictures. https://www.cyclingweekly.com /news/latest-news/tom-simpson-life-pictures-146298 accessed: 26 June 2019.

Wiggins, B., 2012. In Pursuit of Glory. London: Orion.

Wilcockson, J., 2006. The Tour de France 2006: Triumph and Turmoil for Floyd Landis. Colorado: Verlhac Editions. 